\title{
Introdução a um Estudo sobre o "Estudo V - Die Reihe Courante"- para Piano*
}

\author{
Jorge Peixinho
}

O Estudo V ("die Reihe - Courante") foi escrito em 1992 e situase cronologicamente, no âmbito da minha obra de compositor, entre um núcleo de peças, algumas delas para piano, como a "Glosa I" e o "In Folio/ para Constança" (1990-92), outras para conjuntos instrumentais -"Mediterrânea" e"Floreal" -, além de uma obra demúsica eletrônica, "A Floresta Sagrada", de 1992.

O fato da composição destas obras situar-se num período tão curto de tempo (apenas três anos) não obsta a que qualquer delas - e o "Estudo $V$ ' em particular - possua um cunho muito peculiar e um rosto inconfundível. Tal não significa, é evidente, a inexistência de laços de parentesco, não só entre as obras mencionadas, como também com outras situadas antes e depois do período referido (otriênio 1990-1992). Esses laços existem seguramente, eu assumo-os, e considero que não seria possível nem desejável anulá-los: elementos estilísticos comuns, gestos eimpulsos muito concretos no misterioso domínio da criatividade, problemas e preocupações típicas do compositor (propostas e soluções técnicas, opções estéticas), equilíbrio entre rigor e liberdade, fantasia e autodisciplina e tantas outras.

$\mathrm{O}$ "Estudo V" herda, assim, sempre qualquer coisa de obras minhas anteriores e deixa traços em obras posteriores. Encontramos embrionariamente, empeças como "Villalbarosa" e "Glosar", elementos estilísticos queirão atingir uma sistemática plenitudeno "Estudo V",

* Esta obra foi apresentada em primeira audição mundial no XI Seminário Internacional da Músiç, UFBa, em Salvador, no dia 20 de setembro de 1993 e ém primeira européia no Instituto FrancoPortugais de Lisboa, no dia 11 de outubro do mesmo ano pelo pianista José Eduardo Martins. 
do mesmo modo que, nesta última obra, antever-se-ão gérmens de figuras e situações musicais que irão constituir pontos nucleares numa composição posterior ("Nocturno no Cabo do Mundo"), de 1993.

$$
* * *
$$

Como qualquer Estudo que se preze, e tomando como referência histórica os exemplos magistrais deChopin, Liszt ou Debussy, uma peça com este título deve conter dois vetores fundamentais, a saber: ser um "estudo" simultaneamente de execução para o instrumento respectivo (neste e naqueles casos, o piano) e para o compositor igualmente, como laboratório de novas experiências e dilatação dos seus limites técnicoexpressivos.

Passemos a analisar sumariamente estes dois aspectos (obviamente, complementares entre si) no "Estudo V".

No plano da técnica instrumental, ele pretende constituir um verdadeiro "estudo" de novos processos de execução, bem como um aprofundamento de princípios técnicos composicionais:

a) trilos encadeados em glissandos direcionais (em "cascatas" descendentes e ascendentes):

Ex. 1

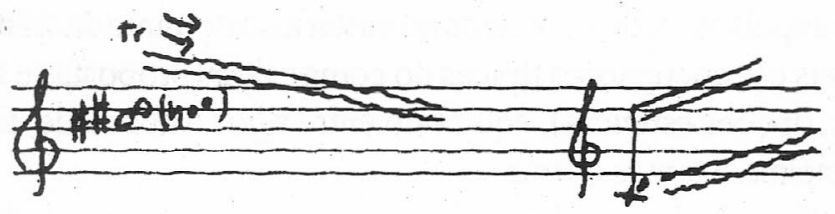

b) movimentos aleatórios em $3^{\text {as }}$ (arpejadas ou não) ou em $4^{\text {ass: }}$

Ex. 2

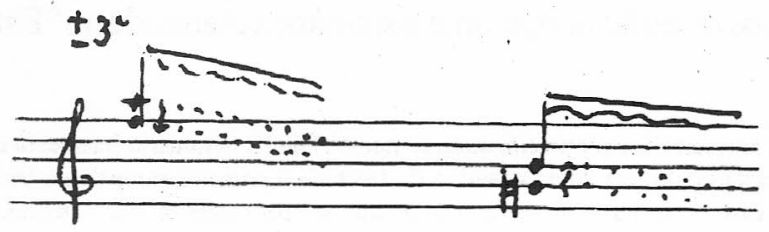


c) glissandos maciços com a mão aberta:

Ex. 3

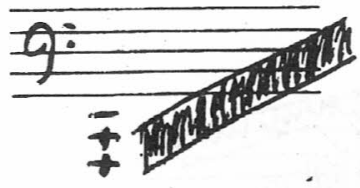

d) permutações de desenhos melódicos ad libitum:

Ex. 4

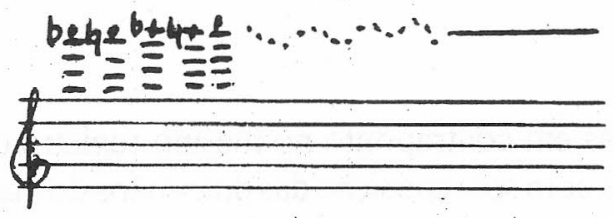

e) movimentos descendentes "em cascata" com permutaçōes internas num âmbito fixo ou homogêneo:

Ex. 5

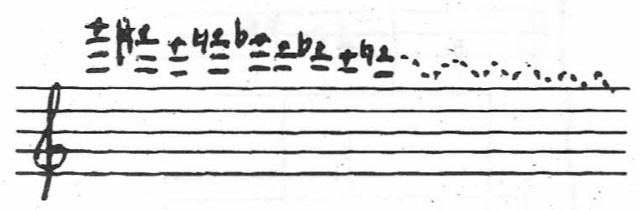

f) chusters com movimento interno aleatório:

Ex. 6

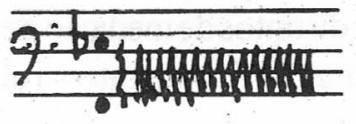

g) glissandos de clusters "em cascata" com movimentos internos aleatórios:

Ex. 7

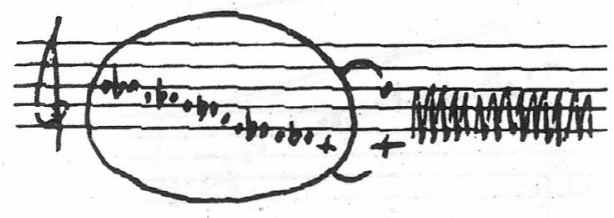


h) trêmolos aleatórios em glissando:

Ex. 8

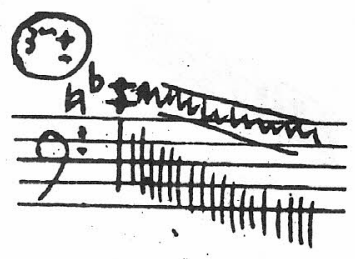

II

1) polifonias em contraponto no mesmo registro (o que implica uma coexistência com sobreposição das duas mãos do pianista), diferenciadas entre si por dois níveis dinâmicos:

Ex. 9

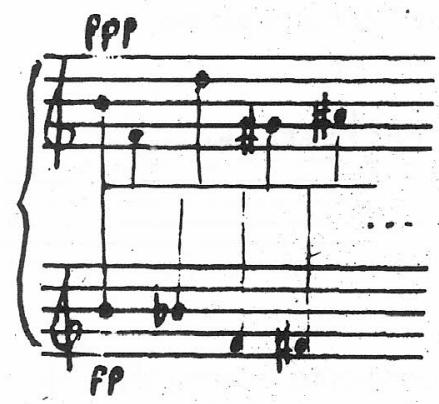

2) sobreposição de tipos distintos demedição detempo (mensurado / aleatório - flexível, rápido regular / moderato - rubato etc.):

Ex. 10

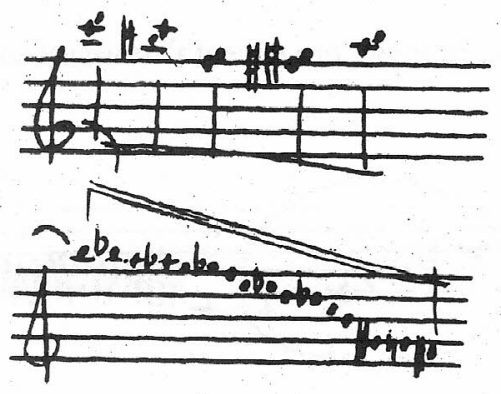


3) sobreposição de técnicas de execução distintas:

Ex. 11

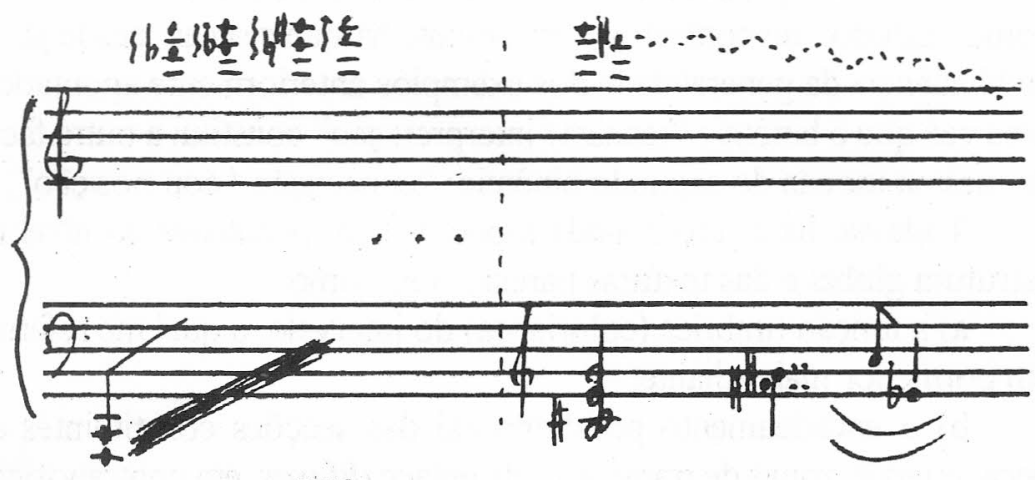

4) escalas cromáticas sobrepostas em translação "semi-aleatória"

Ex. 12
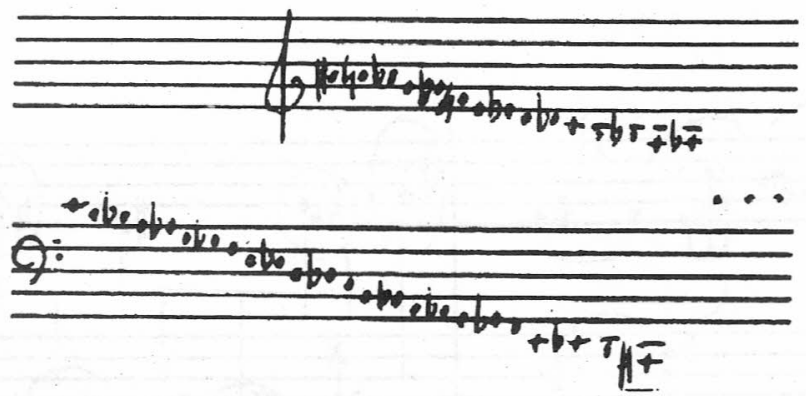

5) movimentos em $3^{\text {as }}$ com defasamento entre as duas mãos:

Ex. 13
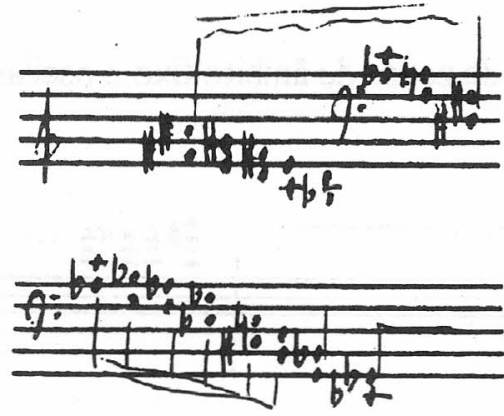
Quanto ao que se refere à problemática específica do compositor, como "estudo" de conceitos e processos, há que realçar, desde já, a ambivalência da generalidade dos exemplos anteriormente apontados, uma vez que o binômio "técnica / interpretação" constitui a outra face da mesma moeda do segundo binômio: "concepção / composição".

Todavia, há a referir ainda aspectos bem peculiares ao nível da estrutura global e das texturas parciais, tais como:

a) a função tímbrica (colorística) do intervalo, à qual me referirei em pormenor mais adiante;

b) o encadeamento poli-temporal das secções constituintes da peça, criando zonas de transição e de enlace difusas, em contraposição com os momentos de recorte nítido, claro e unívoco.

c) a valorização do registro como fator determinante da estrutura composicional;

d) a criação de espaços ambíguos ("entrelaçados"):

Ex. 14

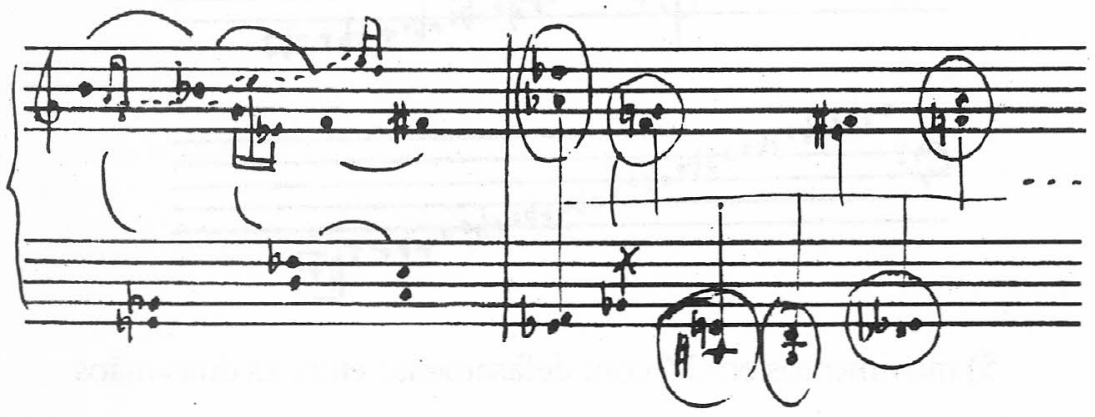

e) a utilização de zonas de âmbito fixo e oscilante;

Ex. 15

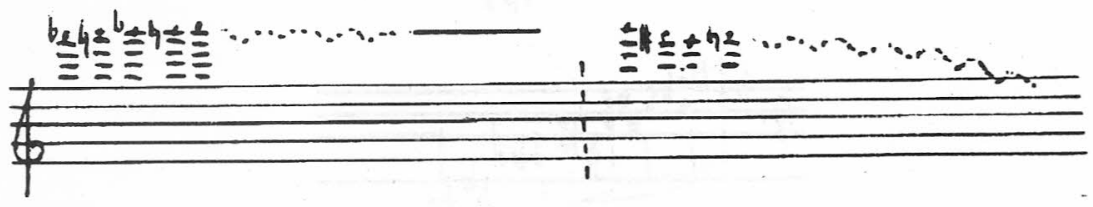


f) as novas relações instauradas entre planos distintos simultâneos, hierarquicamente distribuídos:

Ex. 16

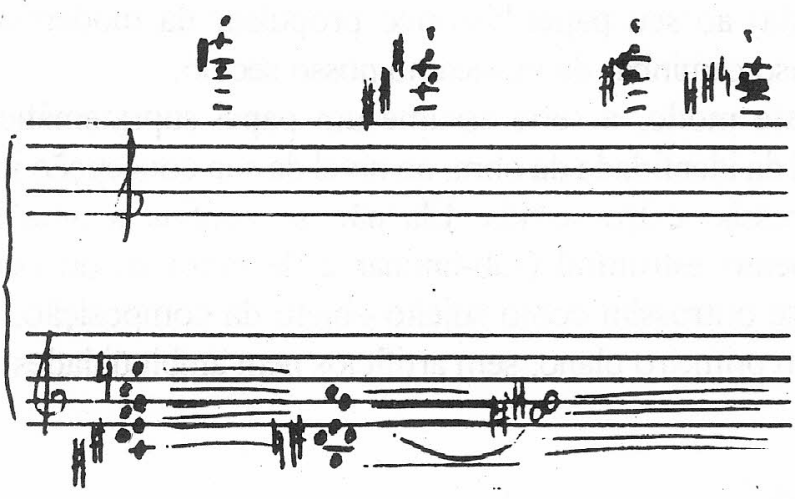

Finalmente, e acima de tudo, é de assinalar a presença constante e quase avassaladora da série ("die Reihe"), constituindo esta o núcleo, a raiz e a fonte primacial da obra, ao mesmo tempo que assume uma função emblemática e simbólica. E se considerarmos também, metaforicamente, a série como uma imagem (visível, reconhecível e projetável em mil reflexos), então poderemos transpô-la ainda para uma dimensão iconográfica.

Estas reflexões conduzem-nos a um novo capítulo, que pretende esclarecer as razões profundas do subtítulo do "Estudo V", iluminandothe os aspectos mais significativos.

$$
* * *
$$

"die Reihe"

Trata-se de um estudo sobre uma visão da série como objeto e sujeito, uma perspectiva abrangente que compreende tanto a concepção schöenberguiana da série-tema, como a concepção weberniana da série como princípio estrutural e estruturante, ordenador e motor da organização da obra.

E, no entanto, não se trata de uma obra serial! O "Estudo V" 
pretendeseruma reflexão sobreo profundo significado histórico emítico da série, a série reificada e simbólica, uma visão crítica dos seus pressupostos teóricose filosóficose, ao mesmo tempo, uma homenagem (comovida) ao seu papel histórico propulsor da modernidade neste vertiginoso caminhar da música no nosso século.

Deste modo, a série assume um papel supratemático e vetor essencial da identidade da obra, ao nível da sua concepção interna e da sua expressão extro-vertida. Ela não se confina a uma função de ordenamento estrutural (sub-liminar e de certo modo oculta), mas assume-se outrossim como sujeito-objeto da composição, ostensivamente em primeiro plano, sem artificios nem ambigüidades.

\section{"Courante"}

Há que entroncar esta peça na concepção barroca da continuidade discursiva, dentro de uma lógica de espaços que se projetam uns nos outros, sem limites pré-fixados. A "Courante" das suítes barrocas simboliza essa continuidade; tal como a corrente de um rio que flui e se espraia ${ }^{(1)}$, tal como uma corrente de laços encadeados e interligados.

As relações ternárias e binárias da Courante barroca são aqui transpostas e assimiladas à totalidade dodecafônica (12 como múltiplo de 2 e de 3 ). Doze como número das suas secções (6x2); dezoito como número das suas subdivisões internas $(6 \times 3)$. Aí todo o edificio se constrói, se autojustifica, se ex-porta, toda a arquitetura seclarifica, todo o seu (profundo) significado se ilumina.

$$
* * *
$$

Nesta obra, a série ("die Reihe") é apresentada sem transposições ${ }^{(2)}$ (excetuando os redobramentos em paralelo da série original), apenas utilizando operações simples de inversão e retrogradação (confinadas a situações topologicamente definidas) e processos vários de permutação, dedução e desenvolvimento, espécie de autogênese variável sob forma de rotação ou de espiral. Exemplos destes processos serão apresentados no capítulo dedicado à análise da $1^{\mathrm{a}}$ secção. 
A pluralidade de planos no mesmo registro segue também critérios de diferenciação fundados sobre dois ou mais níveis dinâmicos, alternâncias, relações rítmicas regulares ou irregulares (distribuídas simétrica ou assimetricamente), emprego de apogiaturas ou grupetos etc.

$$
\text { * * * }
$$

Há pouco aludi também a um dos aspectos mais relevantes e significativos desta peça, no que respeita à sua técnica de escrita.

Pode-se dizer que, de um modo geral, e através de múltiplas variantes, o intervalo ocupa um papel primordial na composição da obra. O intervalo não é apenas determinante enquanto componente básico da estrutura da série, mas assume também (e particularmente) um valor colorístico e funcional relevante e insubstituível.

Através dos processos de redobramento, ele define campos harmônicos fixos ou variáveis:

- homogêneos (ex: $2^{\text {as }} \mathrm{m} / 2^{\text {as }} \mathrm{M} / 3^{\text {as }} \mathrm{m} / 3^{\text {as }} \mathrm{M}$ )

Ex. 17

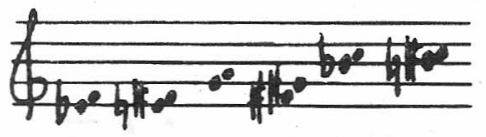

- semi-homogêneos ( $2^{\text {as }}$ - m. ou M. / $3^{\text {as }}$ - m. ou M.)

Ex. 18

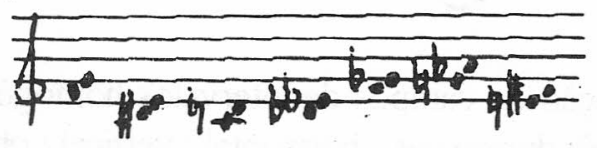

- variáveis direcionais - por dilatação ou contração do intervalo (progressivas ou ondulantes)

Ex. 19

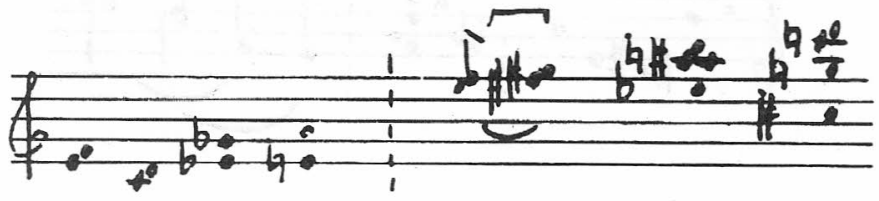


- variáveis "em random"

Ex. 20

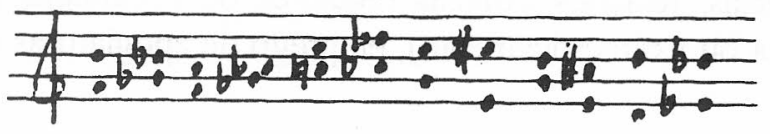

Além dos processos de redobramento, provocando blocos de "espessura" ou densidade variável, o intervalo assume ainda muitas outras funções estruturais, tais como:

a) criação de blocos harmônicos autônomos e de campos momentaneamente polarizados:

Ex. 21
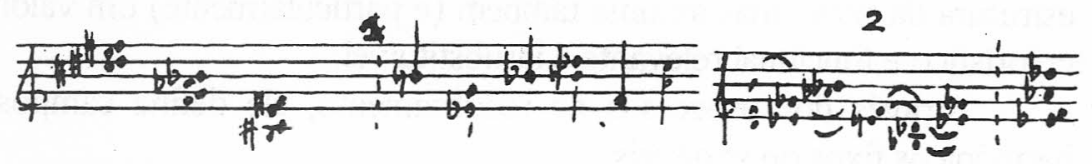

b) formação de desenhos temáticos ou motívicos (vide "tema de órgão"):

Ex. 22

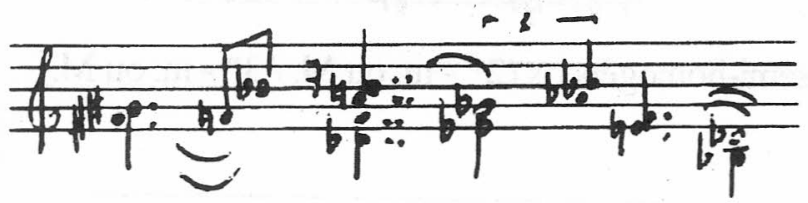

c) definição de campos de intervalos homogêneos (ex: os tons inteiros nas três dimensões - horizontal / vertical / oblíqua:

Ex. 23

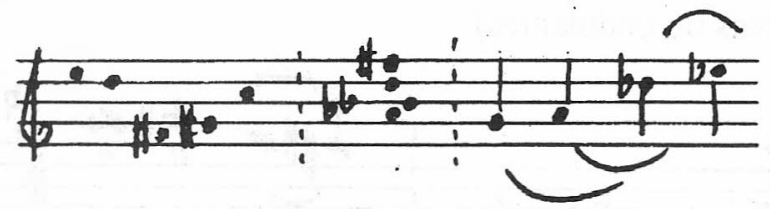


e inferior:

d) projeção melódica através da deslocação das periferias superior Ex. 24

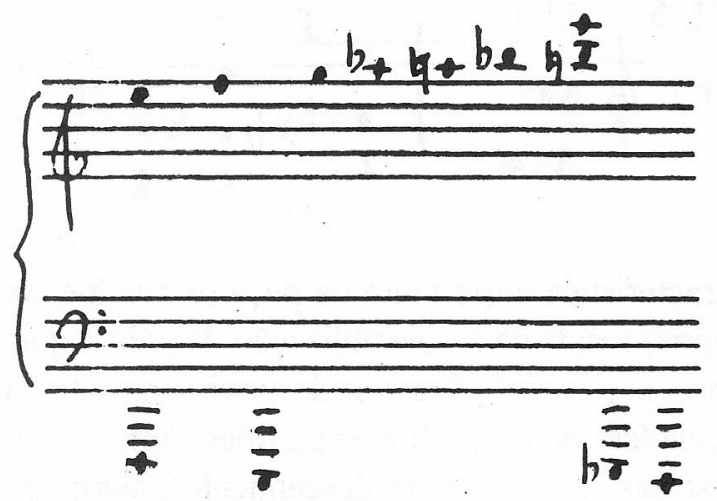

e) aplicação de pedais-fundamentais no registro extremo-grave em deslocação cromática descendente:

Ex. 25

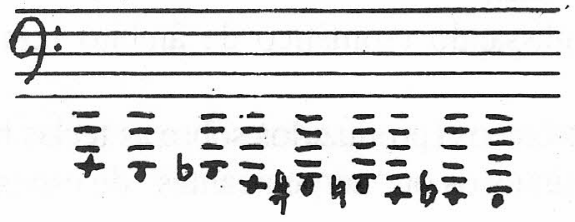

A tẻcnica de manipulação do intervalo como elemento colorístico e funcional articula-secoerentementecom as características estruturantes da série, sendo constante uma interligação e interpenetração entre os dois vetores. É disso exemplo paradigmático a relação estabelecida entre a dilatação e a contração do intervalo - nível real / concreto ${ }^{1}$ - e a "dilatação" e a "contração" (numérica) das alturas da 1 a dedução da série (nível abstrato - lógica "oculta"). ${ }^{2}$

Ex. 26

1)

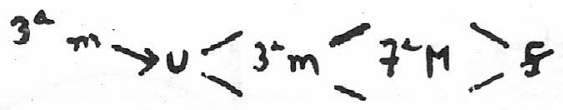

2)

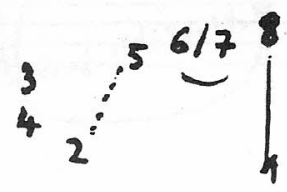




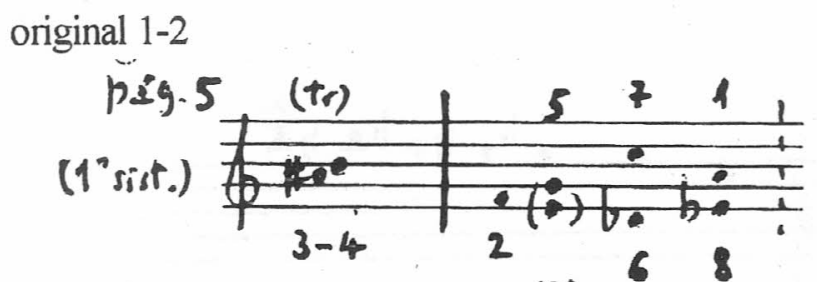

(9)

Outra característica importante da peça (e que lhe confere uma identidade própria) reside na ampla utilização daquilo a que eu chamo "matérias sonoras oscilantes". Trata-se de movimentos direcionais (de âmbitos, velocidades, densidades e expansões variáveis) como uma espécie de "cascatas" (nem sempre descendentes, algumas - como que desafiando a lei da gravidade - também sobem!). Essas "matérias oscilantes" apresentam-se segundo diferentes formas, que passo a enunciar em seguida:

a) escalas cromáticas;

b) chusters em glissando cromático de âmbito homogêneo ou variável;

c) glissandos diatônicos (produzidos sobre as teclas brancas);

d) movimentos sinuosos ou "serpenteantes" de espessura variável:

Ex. 27

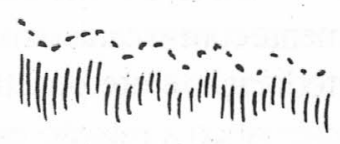

e) bandas fixas de alturas com variantes aleatórias (lineares ou maciças):

Ex. 28

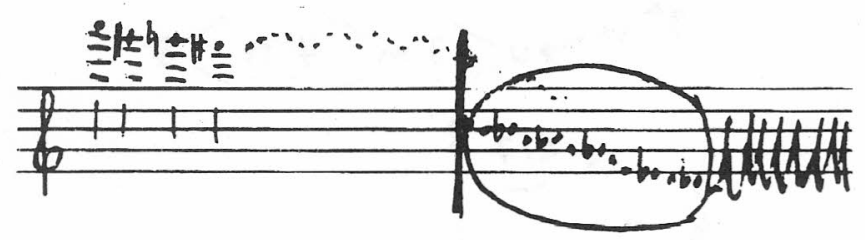


f) trilos simples, trilos complexos com bandas de alturas determinadas e trilos oscilantes em glissando com alturas semideterminadas:

Ex. 29
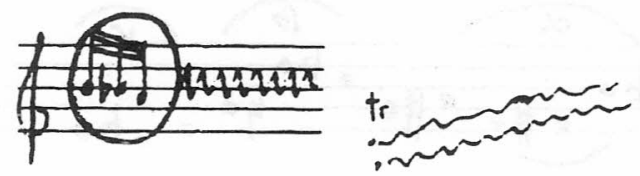

Ainda dentro deste capítulo, desejaria aludir sumariamente às funções distintas que ocupam e desempenham os movimentos cromáticos ao longo da peça, segundo um conjunto de variáveis, nomeadamente o âmbito, a velocidade e a duração global.

É disso exemplo relevante e paradigmático a instauração de pedais intermitentes (fixos ou móveis), que constituem pontos de articulação ao nível da grande forma.

Ex. 30

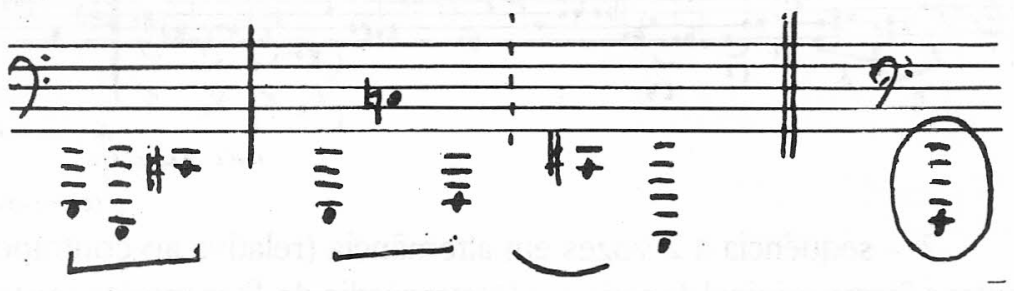

(tricórdios obtidos por transposição e permutação de fragmentos da série)

A finalizar este estudo, apresentarei uma análise formal mais detalhada deuma parte da obra (concretamenteo seu início-a $1^{a}$ secção), começando por enfocar a sua componente matriz, que é, como sabemos, a série ("die Reihe").

A série dodecafônica é exposta logo de início, num segmento que compreende, para além dos doze sons, uma seqüência de outros vinte, correspondentes a uma pequena expansão provocada por deduções do original. Chamemos a esta seqüência de 32 sons "segmento 1". 
Ex. 31 - série original

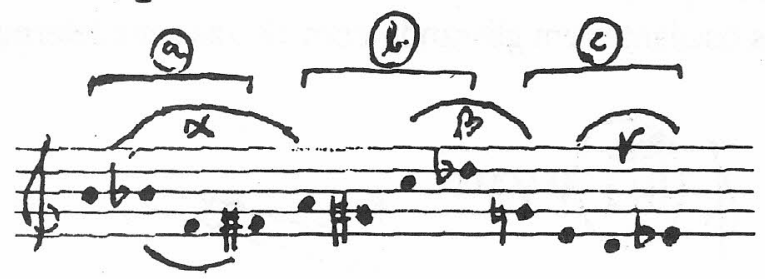

A $1^{\text {a }}$ secção é composta por cinco segmentos, caracterizados, cada um deles, por determinadas particularidades.

$1^{\circ}$ - seqüência monódica de 32 sons $(12+20)$ - já mencionado no parágrafo anterior;

Ex. 32

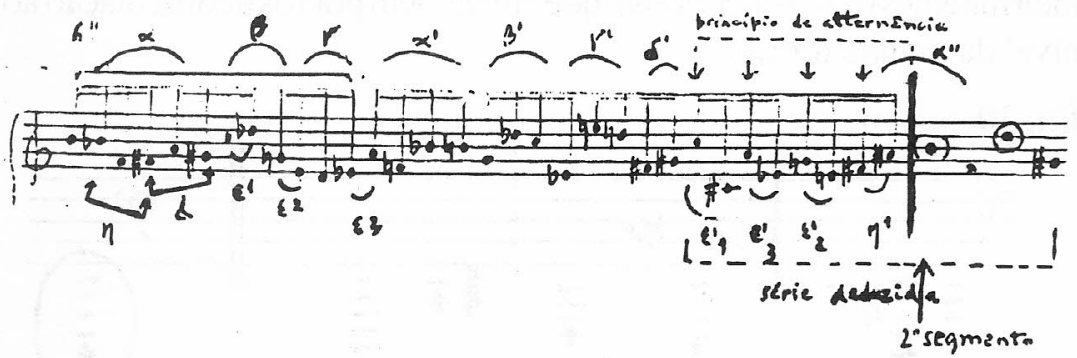

$2^{\circ}$ - seqüência a 2 vozes em alternância (relativa ao contraponto entre a forma original da série $+01^{\circ}$ tetracórdio do $1^{\circ}$ segmento (ao todo, 16 sons) e as deduções derivadas mais ou menos livremente daquela;

- introduz o elemento de sucessão direcional;

Ex. 33 :"

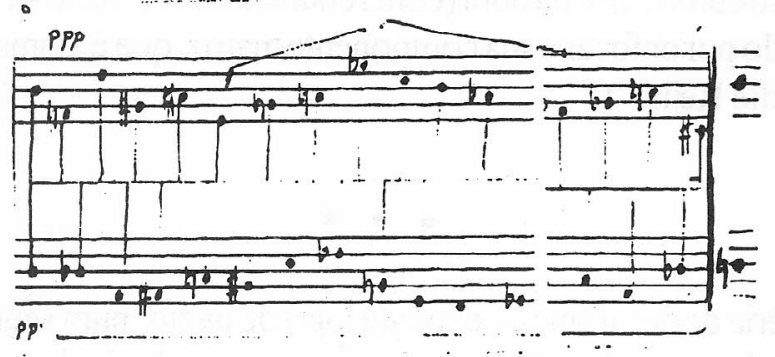


$3^{\circ}$-seqüência de 16 sons (equivalentes àdo segmento anterior) com contraponto duplo em alternância de 2 planos de distinta "espessura" $(1+2)$. A "contraparte" é deduzida livremente da série, utiliza uma 1 " fração de 6 articulações com intervalos variáveis e uma $2^{\mathrm{a}}$ (igualmente de 6) com um intervalo único $\left(2^{\mathrm{a}} \mathrm{M}\right)$.

- emprega também o elemento de sucessão direcional eintroduz o fator rítmico;

\section{Ex. 34}

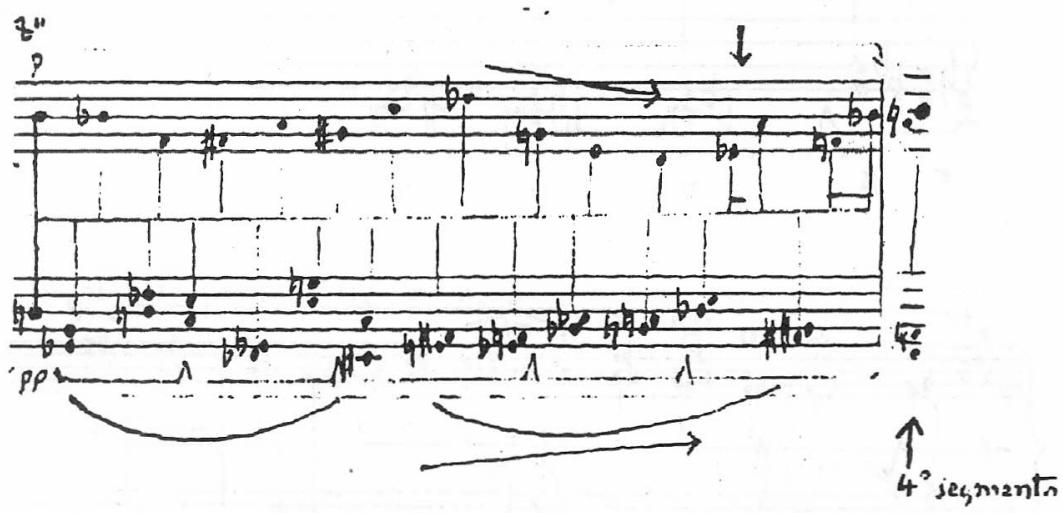

$4^{\circ}$ - contraponto a duas dimensões em alternância com "espessuras" constantes (dois sons em cada plano). O nível principal contém 26 articulações (12+14) e o nível secundário, 20. Com 4 sincronizações, podemos assinalar um total global de 38 articulações, às quais se deverão adicionar três apogiaturas e uma prolongação, num total de 42 elementos básicos.

Os dois planos encontram-se estreitamente interpenetrados e apresentam características ligeiramente distintas ao nível dos intervalos. De fato, o plano principal emprega livremente $2^{\text {as }}, 3^{\text {as }}$ e $4^{\text {as }}$, enquanto o plano secundário se detém com maior rigor numa alternância de $2^{\text {as }} \mathrm{e} 3^{\text {as }}$, constituindo microcampos intervalares, irregulares e mais ou menos homogêneos. 
Ex. 35
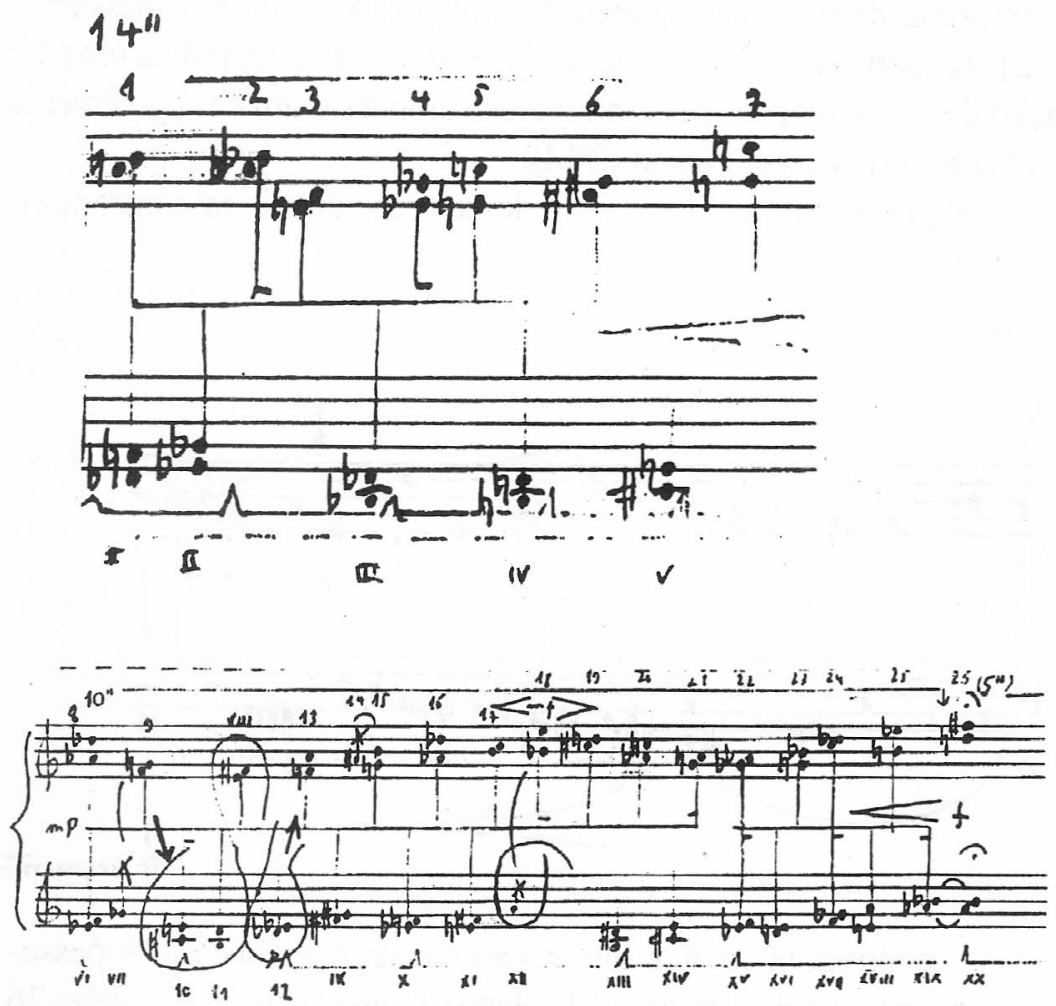

$5^{\circ}$ - contraponto a duas dimensões alternando as situações de contraposição entre os planos com as de sincronização, traduzindo, deste modo, um aumento progressivo de densidade ("espessura" vertical projetada no tempo). O total global de articulações é de 40 $(36+4)$, introduzindo este segmento as apogiaturas complexas (6), as primeiras cinco formadas por dois sons e a última, por 4.

- os intervalos aproximam-se progressivamenteda homogeneidade ( $2^{\text {as }}$, com predominância das Maiores, como intervalo privilegiado; $3^{\text {as }}$, com predominância das menores, como intervalo secundário; e $4^{\text {as }}$ esporadicamente). 
Ex. 36
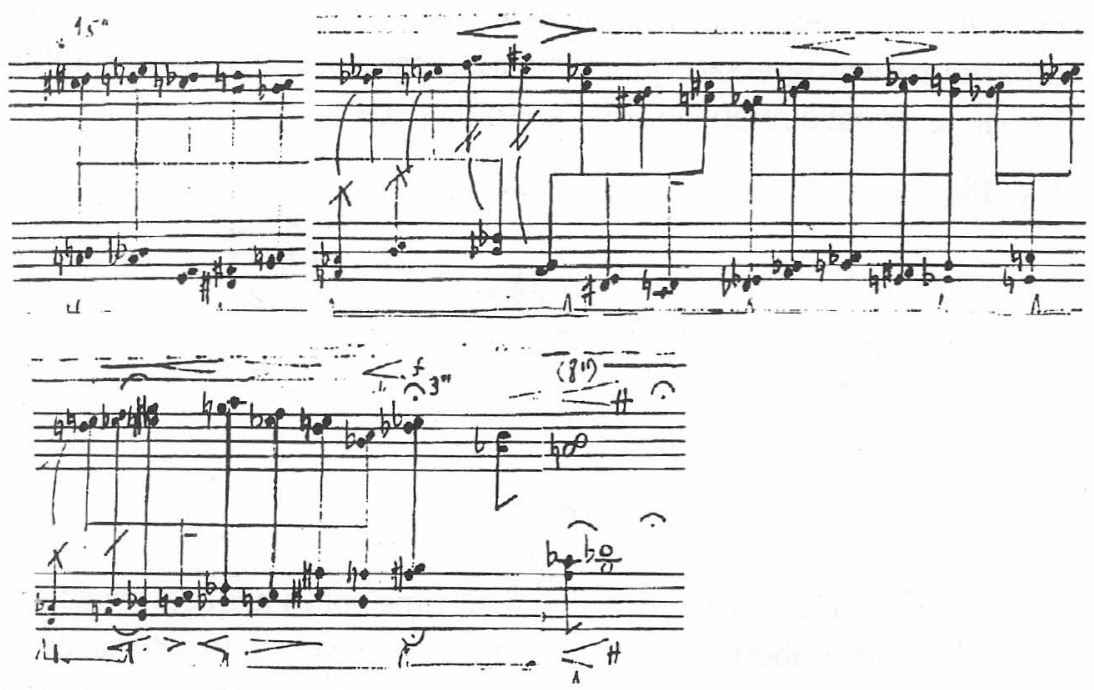

Por último, e numa perspectiva mais geral e abrangente, é de referir alguns dos aspectos fundamentais que caracterizam esta secção:

a) um aumento progressivo de densidade - do nível 1 ao nível 4 com base na seqüência seguinte: sucessão, alternância e simultaneidade; b) um progressivo alargamento da duração dos seus segmentos:

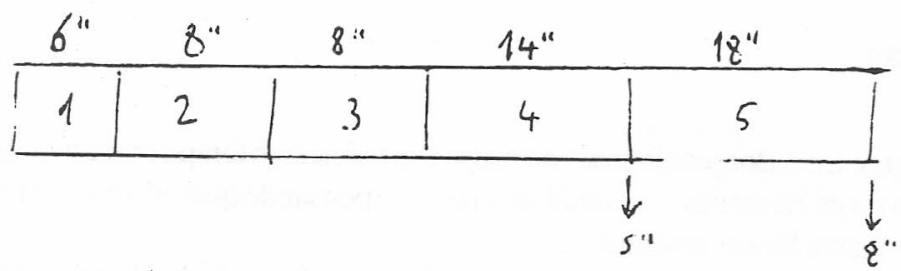

c) uma subida constante da sua periferia superior, em direção ao $\mathrm{Si}_{\mathrm{b}}{ }^{6}$, uma $7^{\mathrm{a}} \mathrm{M}$ acima do $\mathrm{Si}$ inicial:

Ex. 37

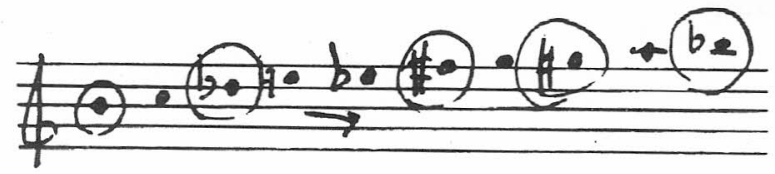


Esta ascensão preenche, numa primeira fase, o limite do total cromático (dodecafônico), ultrapassando-o na seção seguinte através de uma rigorosa progressão, que culmina logicamente no $\mathrm{Si}^{6}$, queéa altura inicial, terminal e referencial ao longo da peça.

Ex. 38

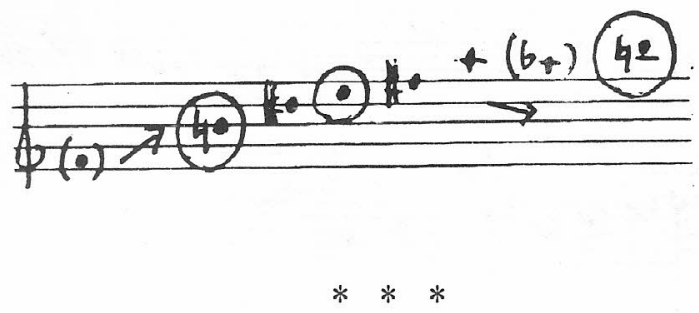

Com o "Estudo V", descrevi mais uma curva naquela espécie de espiral sempre aberta, que constitui, a meu ver, a trajetória de um compositor. Como outras obras marcantes na minha produção criadora, ela fecha e abre simultaneamente velhas e novas etapas, criando uma ponte entre duas margens de umrio; umrio sempre vivo eem movimento, uma corrente ininterrupta em direção a um novo infinito, metáfora da impossível utopia da perfeição e da liberdade criadora.

\section{Notas}

1. Jorge Luís Borges afirma: "na nossa experiência, o tempo corresponde sempre ao rio de Heráclito..."; e mais adiante: "... e pensando que o rio nãoé o rio porque as águas foram mudando..."

2. As transposições que se encontram disseminadas ao longo da peça reportam-se exclusivamente ao nível micro-estrutural (fragmentos da série inseridos intersticialmente no contexto global).

Jorge Peixinho, compositor, pianista e professor do Conservatório Nacional Lisboa - Portugal 